\title{
Francisco Javier Barreto Schmedling
}

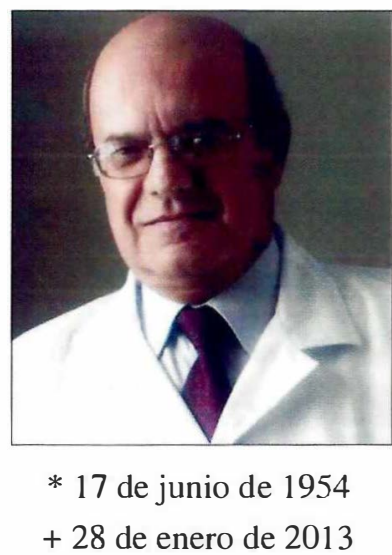

El Dr. Francisco Javier Barreto estudió en el Colegio San Carlos de Bogotá. Siendo un bachiller adolescente ingresó a estudiar medicina en el Colegio Mayor de Nuestra Señora del Rosario en febrero de 1978. Médico muy joven hace el año rural en su querida población de Ubaté, ese mismo año contrae matrimonio con Hilda González su adorada e inseparable compañera, tuvieron dos hijos:Silvia y Daniel.

Silvia: médica, su prematuro fallecimiento nos dejó una marca imborrable a todos los que la conocimos, sólo Dios sabe cómo los afectó esta pena. Daniel: casado con Christine, viven en Escocia y hace un año tuvieron una hija a quien llamaron Silvia que ha sido el renacer de la familia, la nieta a quien el Dr. Barreto adoraba y disfrutaba hasta el día de su fallecimiento en Ubaté.

Terminados sus estudios de medicina quería ser geriatra, pero es posible que por su gran cercanía con la medicina interna hizo esta especialidad en el Hospital de San José, concluyéndola en1980. Continuó con nefrología siendo el primer alumno del Dr. Eduardo Carrizosa y desde entonces se vinculó al Servicio de Nefrología del Hospital de San José. Con el Dr. Carrizosa entablaron una amistad inseparable, confidentes, siempre se mantuvieron en continuo diálogo, generaron una fuerza aditiva en conjunto con el Dr. Hernando Altahona en la formación de médicos, internistas y nefrólogos integrales, que han dejado huella en la historia de esta especialidad en el país y en cada uno de los que fuimos sus alumnos, muchos de ellos líderes de la nefrología de Colombia. Su participación en el crecimiento y prestigio del servicio del hospital, sobre todo en las áreas de diálisis y trasplante renal es invaluable.

Obtiene de la Asociación Colombiana de Medicina Interna el galardón de "Excelencia en Medicina Interna" en 1990, es reconocido también en el Hospital de San José con el premio "Sallie de Cubillos", llegó a ser Profesor Titular de medicina en la Universidad del Rosario y en la Fundación Universitaria de Ciencias de la Salud, donde continuó su carrera docente en 1990 y ocupó la Vicerrectoría Académica. En sus enseñanzas fue un verdadero "maestro", su ejemplo fue el mejor estímulo para nuestra formación.

Ocupó la jefatura del servicio de nefrología de 1986 a 1992, la dirección del departamento médico del Hospital de San José de1992 a 1997, fue Miembro Fundador de la Sociedad Colombiana de Trasplante de Órganos, Presidente de la Sociedad Colombiana de Nefrología (hoy Asociación), perteneció a las Sociedades Latinoamericana de Nefrología e International Society of Hypertension y Miembro Asociado de la Sociedad de Cirugía de Bogotá. Fue editor de varios libros, entre ellos uno con los Drs. Ricardo Durán, José Ignacio Hernández y Hernando Altahona, las dos ediciones de Seminarios en Medicina, y hace poco con el Dr. Mauricio Ruíz, en los Fundamentos en Medicina - Nefrología, 5 a Edición de la Corporación de Investigaciones Biológicas, donde se destaca su directriz para llevar la nefrología a los estudiantes panamericanos de medicina, más que tratar de ser un libro especializado para una minoría.

Retirado del Hospital de San José ocupó los cargos de Director Médico de la empresa Fresenius Medical Care Colombia de 1998 al 2008 y después el mismo cargo hasta su deceso en la Fundación Esensa.

Gratos e imborrables recuerdos nos deja el Dr. Barreto, su fino humor que resaltaba su brillante inteligencia, su prodigiosa memoria, su caballerosidad y decencia y sobre todo sus consejos, siempre con una envidiable rectitud en sus pensamientos, verticalidad y ética jamás negociables.

Amigo incondicional y crítico racional en las situaciones complicadas. Su especial don de gentes, término difícil de explicar pero entendible, hará que lo extrañen los campesinos vecinos de su casa de Ubaté, sus pacientes que tanto lo querían, sus compañeros de trabajo en las áreas de administración y de enfermería, los médicos, estudiantes, su muy unida familia y sus amigos.

Hilda, Daniel y familia: orgullosos han de sentirse de haber tenido a su lado a un hombre como Pacho, que dejó una huella muy profunda en cada una de las personas que lo conocimos y tuvimos el privilegio de compartir con él algunos momentos de nuestra vida.

“.. y aunque la vida perdió dejónos harto consuelo su memoria..”(Antonio Machado)

Carlos Rosselli Sanmartín Alumno de Francisco y actual Jefe del Servicio de Nefrología del Hospital de San José, Sociedad de Cirugía de Bogotá. 